\title{
PERSONALITY AND ATTITUDES TOWARDS CURRENT POLITICAL TOPICS
}

\author{
Rainer Riemann, ${ }^{*}$ Claudia Grubich, Susanne Hempel, Susanne Mergl and \\ MANFRED RICHTER \\ Universität Bielefeld, Abteilung Psychologie, Postfach 8640, 4800 Bielefeld, Germany
}

(Received 5 September 1992)

\begin{abstract}
Summary-We presented a representative list of 162 political issues currently discussed in Germany and the German NEO-FFI to 184 subjects ( $45 \%$ university students). Principal components analysis of the attitude items reveals four factors which are interpreted as (1) general conservatism, preference for authoritarian punitiveness, (2) social welfare and support of women's equality, (3) liberalism and affirmation of technological progress, and (4) affirmation of increase in taxation for environmental protection and the development of East Europe. The first unrotated factor is identified as general conservatism. The analysis of zero and higher order correlations shows meaningful relationships between political attitudes and personality dimensions. The highest (negative) correlations are found between openness to experience and conservatism. Age and sex effects on political attitudes are reported.
\end{abstract}

Most conceptions of personality include attitudes as a facet of personality (e.g. Allport, 1937; Cattell, 1950; Guilford, 1964; Murray, 1938), thus rendering the general problem of the relation between personality and attitudes meaningless. However, the study of links between broad dimensions of personality and a set of specific attitudes (like publicly discussed political issues) may contribute to our understanding of both personality and attitudes.

The purpose of the present study is to explore the relation between the five-factor model of personality and dimensions of political attitudes. The five-factor model emerged from the works of Fiske (1949), Tupes and Christal (1961), and Norman (1963). The five factors extraversion, agreeableness, conscientiousness, neuroticism, and culture/intellect/openness to experiences can be regarded as basic dimensions for the description of individual differences in personality (for a discussion see Costa \& McCrae, 1992; Eysenck, 1992; Zuckerman, 1992). The five-factor model is closely related to Eysenck's three factor system (e.g. Eysenck \& Eysenck, 1985) which is frequently used in the study of political attitudes. The neuroticism and extraversion dimensions are almost identical in both models, and the psychoticism dimension is consistently negatively correlated with agreeableness and conscientiousness (McCrae \& Costa, 1985a).

The relation between personality characteristics and political attitudes has been addressed in numerous studies. Most of these studies focus on Eysenck's two factor theory of attitude structure (e.g. Eysenck \& Wilson, 1978) and the correlation of authoritarianism, dogmatism, machiavellianism, and similar constructs with political attitudes.

Although it is difficult to summarize the relationships between personality dimensions and political attitudes without considcring the different facets of political attitudes, a search through the literature reveals trends which may serve as a background for the interpretation of the present results. Extraversion tends to be negatively correlated with general conservatism and most of its facets (Wilson \& Brazendale, 1973; Pearson \& Greatorex, 1981), although inconsistent results have been reported by Powell and Stewart (1978) in a study of children. A weak positive correlation was observed between neuroticism and ethnocentrism-intolerance (Wilson \& Brazendale, 1973) and a consistent positive relationship was found between neuroticism and dogmatism (e.g. Rokeach, 1960; Smithers \& Lobley, 1978). We did not find any direct evidence concerning the correlation between agreeableness and conscientiousness and political attitudes. As agreeableness and conscientiousness are both negatively related to psychoticism, studies including psychoticism as a personality dimension may be relevant here. However, the correlations between psychoticism

\footnotetext{
* To whom correspondence should be addressed.
} 
and political attitude dimensions are inconsistent. Wilson and Brazendale report a weak positive correlation of psychoticism with conservatism and no correlation with realism versus idealism, whereas Pearson and Greatorex found a moderate negative correlation with conservatism and a positive correlation with realism. Powell and Stewart report consistent negative correlations with conservatism and religion in children and positive correlations with ethnocentrism and punitiveness.

Eysenck (1954) and Eysenck and Wilson (1978) suggested a two dimensional structure of political attitudes: a radicalism-conservatism (left-right) dimension and a tough-mindedness versus tendermindedness continuum. They regard the latter dimension as a projection of personality traits (especially psychoticism, Eysenck \& Eysenck, 1976) onto the domain of political attitudes. Kline and Lapham (1991) suggest tough-mindedness as a term for the opposite pole of agreeableness. Thus a close relation between agreeableness and an attitude dimension orthogonal to conservatism may be expected, although this argument is purely based on semantic relations between concepts.

Central facets of authoritarianism and dogmatism may be regarded as the opposite pole of openness to experience (McCrae \& Costa, 1985b). In addition, there is ample evidence that authoritarianism and dogmatism are correlated with conservatism. This leads to the hypothesis that openness is negatively correlated with conservative attitudes. Although the correlation between political attitudes and openness to experience has not been studied directly, the available indirect evidence supports this hypothesis. Costa and McCrae $(1977,1978)$ found a substantial negative correlation between a measure of traditional family ideology and openness, and small but significant correlations of openness with economic and religious values. Several studies report a high correlation of sensation seeking (Zuckerman, 1979) to conservatism (Glasgow, Cartier \& Wilson, 1985; Kish, Netterberg \& Leahy, 1973; Looft, 1971; Pearson \& Sheffield, 1975). This dimension correlates with extraversion but is also substantially related to openness to experience (McCrae, 1987). Particularly the subscale experience seeking correlates with conservatism and openness.

In addition to the study of linear relations, several studies addressed the question of curvilinear relationships between political attitudes and personality characteristics. Eysenck and Coulter (1972), Ray (1979, 1985), and Heaven and Connors (1988) provide evidence that supporters of right- and left-wing parties differ from supporters of more moderate "center" parties by scoring higher on measures of tough-mindedness. Based on the negative correlations between psychoticism and agreeableness and conscientiousness, we expect negative correlations between these dimensions of the five-factor model and the extremity of political attitudes.

The second aim of our study is to test the effects of sex, age, and educational status (student versus nonstudent) on political attitudes. These variables may covary with political attitudes and personality characteristics, and thus the failure to control these demographic characteristics may distort correlations between personality and attitude dimensions. On the other hand, the inclusion of personality variables in the study of age, sex, and education effects on political attitudes may shed some light on mediating processes.

Several studies report a positive correlation between age and political conservatism (e.g. Feather, 1977). Ojha and Sah (1990) compared Indian parents and their children and found a higher degree of conservatism among the parents. Glamser (1974) found that education has a stronger impact on conservatism than age. In addition, he argues that older people have more moderate than conservative political attitudes. Lupfer and Rosenberg (1983) have shown that the correlation between age and conservatism is mediated by the experience of life events (e.g. marriage, parenthood).

In the majority of studies, females were more conservative than males (Eysenck, 1971; Ojha \& Sah, 1990; Wilson, 1975). Some studies, however, report higher conservatism scores for males (Avery, 1988; Ekehammar \& Sidanius, 1982; Furnham, 1985; Sidanius \& Ekehammar, 1980). More specifically, women are more supportive of social welfare issues (Kopinak, 1987), more negative toward social inequality (Ekehammar, 1985), more egalitarian, less racist, and punitive (Ekehammar \& Sidanius, 1982). In addition, women indicated that they worried more about a nuclear war, showed greater support for a nuclear freeze (Zweigenhaft, 1985), and perceived a greater risk of a serious accident from a nuclear power plant than men (Vleeming, 1985). Eysenck (1971) and Ojha and Sah (1990), however, observed higher conservatism scores among females. 
In summary, we expect that the dimensions of the five-factor model are correlated with political attitudes. Negative correlations with conservative views are expected for openness to experience and extraversion, and a positive correlation for neuroticism. Agreeableness is expected to correlate with a dimension orthogonal to conservatism. For conscientiousness and agreeableness, a curvilinear relationship to conservatism is predicled. We expect a positive correlation between age and conservatism and higher conservatism scores for males.

\section{METHOD}

\section{Subjects}

$S$ s were 184 volunteers (104 females, 80 males) with an age range from 17 to 78 years. The age distribution was skewed $(M=32, \mathrm{SD}=14.2$, Median $=26)$ and bimodal (local maxima at 23 and 50 years). Eighty three $S \mathrm{~s}$ were university students. Nineteen students distributed the questionnaires among fellow students, friends, and relatives in partial fulfillment of course requirements.

\section{Measures}

Personality measures. We used the German version of the NEO-Five Factor Inventory (Costa \& McCrae, 1989; Borkenau \& Ostendorf, 1991) to measure the dimensions neuroticism, extraversion, openness to experience, agreeableness, and conscientiousness.

Attitude measures. We adopt the 'catchphrase' approach to attitude measurement (Wilson, 1985; Wilson \& Patterson, 1968). However, the meaning and evaluation of some of the catchphrases used in Wilson and Patterson's Conservatism Scale undergoes rapid changes. In addition, important political issues like the political consequences of the German reunification, state finances, or environmental protection are not covered by the items of the actualized German version of the Wilson-Patterson C Scale (Schiebel, Riemann \& Mummendey, 1984). Thus we decided to compile a list of catchphrases representative for the current political situation in Germany.

Nineteen $S$ s were presented with a list of ministries of the Federal Government. They were asked to consider recently discussed political issucs in relation to the scope of each ministry. In a group discussion, these issues were condensed into items consisting of one or a few words. We took care that an item was not included into the questionnaire if a nearly identical item had been listed before and that, whenever possible, there was a balance of conservative and liberal item formulations. This procedure resulted in a list of 162 items which were listed in a random order. $S$ s were informed that the questionnaire would measure attitudes towards various political topics. They were instructed to spontaneously express their positive or negative evaluation of the catchphrases. A 7 -point scale ranging from Strongly disagree $(-3)$ to Strongly agree $(+3)$ was provided for each catchphrase.

\section{Procedure}

$S$ s were contacted individually by the experimenters who distributed the two questionnaires. The questionnaires were returned to the experimenters.

\section{RESULTS}

Correlations among the items of the political attitude questionnaire were submitted to a principal-components analysis. The first ten eigenvalues explained $12.1,4.8,3.8,3.4,2.6,2.3,2.2$, $2.0,1.9$, and $1.9 \%$ of the variance. We inspected four-, five-, and seven-factor solutions and considered the varimax-rotated four-factor solution to be most interpretable. In addition, the difference between the fourth and the fifth eigenvalue was noticeably greater than the differences among the eigenvalues of factors five, six, seven, and eight. Four factors cxplained $24.1 \%$ of the variance. We computed factor scores for each of the four factors for an unrotated and a varimax-rotated solution. The first factor of the unrotated solution was easily identified as general conservatism with high-loading items approving strong measures against offenders, rejection of social welfare, development of nuclear power plants, and ethnocentrism. The remaining factors were not interpretable unequivocally. Thus we will restrict our presentation of results to the first 
unrotated factor. The factors of the varimax rotated solution were labeled: (1) general conservatism, preference for authoritarian punitiveness (conservatism), (2) social welfare and support of women's equality (social welfare), (3) liberalism and affirmation of technological progress (technological progress), and (4) affirmation of increase in taxation for environmental protection and the development of East Europe (taxation). The 12 items that load highest on each factor are listed in Table 1.

We analyzed the relation between the five-factor model and dimensions of political attitudes in three ways: (a) zero order correlations of demographic variables and personality variables with factor scores were calculated for the rotated and unrotated solutions separately. This analysis is presented for descriptive purposes only. The correlations can hardly be interpreted because several variables are confounded. (b) We computed third order correlations between personality variables and attitude factor scores controlling for age, sex, and educational status and (c) seventh order correlations for each personality and demographic variable with attitude factor scores controlling for the remaining personality and demographic variables. Since the variables are moderately correlated the latter analysis gives some information about the unique contribution of each variable to the explanation of the variance of an attitude dimension.

Table 1. Rotated factor matrix for political attitudes. 12 marker variables for each factor

\begin{tabular}{|c|c|c|c|c|}
\hline \multirow[b]{2}{*}{ Item } & \multirow[b]{2}{*}{ I } & \multicolumn{2}{|c|}{ Factor } & \multirow[b]{2}{*}{ IV } \\
\hline & & II & III & \\
\hline \multicolumn{5}{|l|}{ General conservatism, preference for authoritarian punitiveness } \\
\hline Solitary confinement for terrorists & 0.75 & -0.11 & 0.03 & -0.19 \\
\hline Squatting & -0.72 & 0.31 & -0.11 & 0.12 \\
\hline Demonstrators forbidden disguises & 0.68 & -0.08 & 0.15 & -0.08 \\
\hline Central registration of AIDS sufferers & 0.67 & -0.13 & -0.09 & -0.12 \\
\hline Right to vote for foreigners & $-\mathbf{0 . 5 9}$ & 0.22 & -0.19 & 0.16 \\
\hline Open penal system & -0.58 & 0.09 & 0.04 & 0.25 \\
\hline Parole for offenders & -0.57 & 0.13 & -0.02 & 0.21 \\
\hline Abolition of the Office for the Protection of the Constitution & -0.51 & -0.01 & -0.03 & 0.16 \\
\hline Homosexual marriage & -0.49 & 0.37 & 0.14 & 0.12 \\
\hline Full membership for Germany in the UN Security Council & 0.49 & 0.19 & 0.12 & -0.16 \\
\hline Own home ownership promotion & 0.48 & 0.12 & 0.03 & 0.00 \\
\hline Liberalize the youth penal system & -0.47 & 0.30 & -0.19 & 0.23 \\
\hline \multicolumn{5}{|l|}{ Social welfare/support of women's equality } \\
\hline Child care at work place & -0.04 & 0.51 & -0.11 & 0.07 \\
\hline Promotion of alternative energy sources & -0.07 & 0.49 & -0.02 & 0.13 \\
\hline Youth training places & 0.17 & 0.48 & -0.22 & -0.13 \\
\hline Increase in cycle paths & -0.15 & 0.47 & -0.11 & 0.06 \\
\hline Tightening of the abortion bill & 0.40 & -0.45 & -0.15 & -0.09 \\
\hline EC surplus to USSR & -0.05 & 0.45 & 0.08 & 0.21 \\
\hline Convalescent leave for mothers & 0.07 & 0.45 & 0.23 & 0.00 \\
\hline More child care centers & 0.03 & 0.44 & -0.31 & -0.09 \\
\hline Wage equality & 0.04 & 0.43 & -0.04 & 0.12 \\
\hline Legal claim to preschool places & 0.03 & 0.42 & 0.28 & 0.26 \\
\hline Integration of handicapped in schools & -0.10 & 0.42 & -0.10 & 0.07 \\
\hline Animal mass production & 0.09 & -0.42 & -0.29 & 0.00 \\
\hline \multicolumn{5}{|l|}{ Liberalism and affirmation of technological progress } \\
\hline Work by automaton & -0.04 & -0.08 & 0.61 & 0.26 \\
\hline Promotion of civil space travel & 0.26 & 0.04 & 0.56 & -0.03 \\
\hline Ban on pornography & 0.04 & 0.03 & -0.51 & 0.12 \\
\hline $100 \mathrm{kin} / \mathrm{h}$ ir un Inotor ways & -0.17 & 0.16 & $-\mathbf{0 . 5 1}$ & 0.40 \\
\hline Nuclear energy & 0.38 & -0.30 & $\mathbf{0 . 5 0}$ & -0.08 \\
\hline Nuclear powered satellites & 0.06 & -0.43 & 0.50 & 0.08 \\
\hline Rationalization of work & 0.08 & -0.15 & 0.49 & 0.22 \\
\hline Fast cars & 0.09 & -0.15 & 0.49 & -0.43 \\
\hline Repeal for closing-time law & -0.17 & -0.08 & 0.49 & -0.11 \\
\hline German participation in space labs & 0.30 & -0.06 & 0.48 & -0.10 \\
\hline Civil nuclear technology & 0.27 & -0.14 & 0.45 & -0.10 \\
\hline Ban on carcinogenic substances & -0.05 & 0.15 & -0.44 & -0.03 \\
\hline \multicolumn{5}{|c|}{ Affirmation of increase in taxation for environmental protection and the development of East Europe } \\
\hline Increase in mineral oil tax & -0.15 & -0.01 & 0.06 & 0.73 \\
\hline Tax to support East Germany & 0.11 & -0.09 & 0.01 & 0.57 \\
\hline Money for East Europe & -0.03 & 0.33 & 0.09 & 0.51 \\
\hline Compensation for Poles who did forced labor & -0.44 & 0.25 & -0.05 & 0.48 \\
\hline Cheap flights & 0.13 & 0.03 & -0.05 & -0.48 \\
\hline Traffic prohibition in downtown areas & -0.20 & 0.19 & -0.15 & 0.47 \\
\hline Environmental tax & -0.25 & 0.23 & -0.08 & 0.46 \\
\hline Closing down areas of agricultural land & -0.02 & 0.10 & 0.12 & 0.45 \\
\hline Increase in VAT & 0.02 & -0.26 & 0.38 & 0.45 \\
\hline Motor way toll charges & -0.08 & -0.05 & -0.07 & 0.44 \\
\hline Tax increase on interest income & -0.30 & -0.06 & 0.03 & 0.43 \\
\hline Enlargement of motor way network & 0.32 & -0.21 & 0.25 & -0.42 \\
\hline
\end{tabular}


A general comparison of the analyses for the rotated and unrotated attitude structures (see Tables 2 and 3) reveals that more variance of the first unrotated factor (general conservatism) is explained by personality variables in comparison to the first rotated factor. The opposite finding is observed for the remaining factors where the rotated solution shows a closer relationship to personality variables. When we statistically control the demographic variables, the first unrotated factor is significantly linked to each of the five personality scales, most remarkably to openness to experience. The seventh order correlations show a unique negative relation of openness to experience and agreeableness and a positive relation of extraversion to general conservatism. Neuroticism and conscientiousness are only indirectly linked to conservatism.

The factor conservatism (rotated solution) shows a negative third order correlation with openness to experience and neuroticism and positive correlations with conscientiousness and extraversion. Of these variables, however, only openness to experience and conscientiousness are directly linked to this factor. Openness to experience also shows a close relation to the factor social welfare. Scores on this factor are nearly equally related to agreeableness. Both personality variables uniquely contribute to the explanation of the variance of scores on this factor. Technological progress correlates highest with emotional stability (neuroticism), negatively with agreeableness, and with extraversion. The latter dimension, however, is indirectly related to this factor. Taxation shows significant third order correlations with openness to experience and agreeableness and a marginally significant $(P<0.07)$ correlation with extraversion. For these variables, significant seventh order correlations were found.

We examined curvilinear relationships between attitude dimensions and personality characteristics by correlating the absolute values of the factor scores with the five personality scales. No significant correlations were found for the first unrotated attitude factor. The absolute values of the rotated factor scores for conservatism were positively correlated with age $(r=0.20)$ and conscientiousness $(r=0.22)$. Seventh order correlations indicate that only conscientiousness (partial correlation 0.21 ) contributes independently to the explanation of the variance of extremity on the conservatism dimension. Extremity on the third rotated factor technological progress is

Table 2. Relation of personality dimensions and demographic variables to political attitude factors (unrotated solution)

\begin{tabular}{|c|c|c|c|c|}
\hline \multirow[b]{2}{*}{ Item } & \multicolumn{4}{|c|}{ Factor $^{a}$} \\
\hline & I & II & III & IV \\
\hline \multirow[t]{3}{*}{ Educational statush } & $-0.26^{* *}$ & $-0.17^{*}$ & -0.05 & -0.14 \\
\hline & NA & NA & NA & NA \\
\hline & -0.05 & -0.08 & -0.04 & -0.07 \\
\hline \multirow[t]{3}{*}{$\operatorname{Sex}^{\mathrm{c}}$} & -0.15 & $0.35^{* * *}$ & $-0.23^{*}$ & 0.03 \\
\hline & NA & NA & NA & NA \\
\hline & 0.14 & $0.32^{* * *}$ & -0.15 & 0.04 \\
\hline \multirow[t]{3}{*}{ Age } & $0.35 * * *$ & $0.30 * * *$ & 0.11 & $0.31^{* * *}$ \\
\hline & $\mathrm{N} \Lambda$ & NA & NA & NA \\
\hline & $-0.21^{*}$ & $0.19 *$ & 0.13 & $0.22 *$ \\
\hline \multirow[t]{3}{*}{ Neuroticism } & $-0.24 * *$ & $0.18^{*}$ & $-0.30^{* * *}$ & -0.05 \\
\hline & $-0.23^{* *}$ & 0.09 & $-0.25^{* *}$ & -0.07 \\
\hline & -0.12 & 0.16 & $-0.23^{*}$ & -0.08 \\
\hline \multirow[t]{3}{*}{ Extraversion } & 0.13 & -0.06 & 0.09 & $-0.20^{*}$ \\
\hline & $0.24^{* *}$ & 0.04 & 0.11 & -0.13 \\
\hline & $0.28 * *$ & 0.08 & 0.02 & $-0.19^{*}$ \\
\hline \multirow[t]{3}{*}{ Openness to experience } & $-0.57^{* * *}$ & $-0.23^{*}$ & 0.03 & -0.01 \\
\hline & $-0.50^{* * *}$ & -0.15 & 0.09 & 0.12 \\
\hline & $-0.49^{* * *}$ & $-0.20^{*}$ & 0.08 & 0.09 \\
\hline \multirow[t]{3}{*}{ Agreeableness } & $-0.27^{* *}$ & 0.08 & 0.16 & $0.26 * *$ \\
\hline & $-0.27^{* *}$ & 0.14 & 0.16 & $0.30^{* * *}$ \\
\hline & $-0.23^{*}$ & $0.19 *$ & 0.13 & $0.29 * *$ \\
\hline \multirow[t]{3}{*}{ Conscientiousness } & $0.35^{* * *}$ & $0.21 *$ & 0.08 & $0.19^{*}$ \\
\hline & $0.23^{* *}$ & 0.06 & 0.05 & 0.07 \\
\hline & 0.13 & 0.09 & -0.01 & 0.09 \\
\hline
\end{tabular}

${ }^{*} P<0.05 ; * * P<0.01 ; * * * P<0.001$.

The first row per variable gives the zero order correlation with the attitude factors. In the second row third order correlations are presented between personality variables and attitude dimensions controlling for sex, educational status and age. In the third row seventh order correlations are listed, holding constant all remaining personality and demographic variables. "The first factor was identified as general conservatism, the interpretation of the remaining factors was not clear.

bstudents vs nonstudents. Students were coded one, nonstudents zero.

'Women were coded one, men zero. 
Table 3. Relation of personality dimensions and demographic variables to political attitude factors (rotated solution)

\begin{tabular}{lcccr}
\hline & \multicolumn{4}{c}{ Factor $^{*}$} \\
\cline { 2 - 5 } Item & $\mathrm{I}$ & $\mathrm{II}$ & $\mathrm{III}$ & $\mathrm{IV}$ \\
\hline Educational status $^{\mathrm{b}}$ & $-0.34^{* * *}$ & 0.06 & 0.01 & 0.03 \\
& $\mathrm{NA}$ & $\mathrm{NA}$ & $\mathrm{NA}$ & $\mathrm{NA}$ \\
Sex & -0.14 & -0.02 & 0.03 & -0.03 \\
& 0.03 & 0.04 & $-0.42^{* * *}$ & -0.14 \\
Age & $\mathrm{NA}$ & $\mathrm{NA}$ & $\mathrm{NA}$ & $\mathrm{NA}$ \\
& 0.10 & 0.06 & $-0.35^{* *}$ & -0.11 \\
Neuroticism & $0.56^{* * *}$ & -0.05 & -0.07 & 0.04 \\
& $\mathrm{NA}$ & $\mathrm{NA}$ & $\mathrm{NA}$ & $\mathrm{NA}$ \\
Extraversion & $0.40^{* * *}$ & 0.03 & -0.04 & 0.09 \\
& -0.17 & -0.01 & $-0.37^{* * *}$ & -0.12 \\
& $-0.25^{* *}$ & -0.02 & $-0.29^{* *}$ & -0.08 \\
Openness to experience & 0.11 & 0.05 & $0.26^{* *}$ & 0.16 \\
& -0.01 & 0.00 & $0.21^{*}$ & -0.16 \\
& 0.18 & -0.01 & $0.19^{*}$ & -0.16 \\
Agreeableness & 0.16 & -0.05 & 0.14 & $-0.26^{* *}$ \\
& $-0.50^{* * *}$ & $0.25^{* *}$ & -0.09 & $0.26^{* *}$ \\
& $-0.38^{* * *}$ & $0.24^{* *}$ & -0.12 & $0.30^{* *}$ \\
Conscientiousness & $-0.40^{* * *}$ & $0.20^{*}$ & -0.07 & $0.29^{* *}$ \\
& 0.02 & $0.25^{* *}$ & -0.17 & $0.29^{* *}$ \\
& 0.08 & $0.25^{* *}$ & $-0.21^{*}$ & $0.29^{* *}$ \\
& 0.17 & $0.20^{*}$ & $-0.23^{*}$ & $0.25^{* *}$ \\
& $0.45^{* *}$ & -0.09 & 0.01 & -0.01 \\
& $0.26^{* *}$ & -0.01 & 0.07 & -0.02 \\
& $0.19^{*}$ & -0.05 & -0.04 & 0.00 \\
\hline & 2.001 & & &
\end{tabular}

$* P<0.05 ; * * P<0.01 ; * * P<0.001$

The first row per variable gives the zero order correlation with the attitude factors. In the second row third order correlations are presented between personality variables and attitudes dimensions controlling for sex, educational status and age. In the third row seventh order correlations are listed, holding constant all remaining personality and demographic variables.

asee text for description of factors.

${ }^{\mathrm{b}}$ Students vs nonstudents. Students were coded one, nonstudents zero.

'Women were coded one, men zero.

positively correlated with age $(r=0.18)$ and negatively with openness to experience $(r=-0.19)$ and extraversion $(r=-0.19)$. The correlation with agreeableness is marginally significant $(r=-0.16, P<0.10)$. Extraversion and agreeableness show the highest third and seventh order correlations, but none of these are significant. Extremity on the remaining two rotated attitude factors shows no significant correlations with demographic or personality variables.

As expected, age has an effect on general conservatism in the unrotated and in the rotated solution. This effect is observed even when personality dimensions are held constant. For the rotated solution, the effect is remarkably high. Educational status (student vs nonstudent) shows sizable zero order correlations with conservatism. These correlations, however, are not significant when we control for age, sex, and personality dimensions. A second interpretable correlation is found between sex and technological progress.

\section{DISCUSSION}

Our analyses revealed a clear structure of a representative pool of items measuring attitudes towards current political issues. The most important finding concerning the relation between personality dimensions and political attitudes is the substantial correlation between openness to experience and conservatism.

The total amount of variance accounted for by the four attitude factors is relatively small. Note, however, that we computed a factor analysis for an item pool that had not been submitted to item analytic procedures before. Although the focus of our attitude items was on current political topics, political attitude factors similar to those found here are reported in the literature. General conservatism emerged as the strongest factor underlying political attitudes, explaining approximately as much variance as the remaining three factors. The remaining factors provide a meaningful differentiation of political attitudes orthogonal to conservatism. Factors similar to our social welfare factor have been described by Kerlinger, Middendorp and Amon (1976) and Sidanius and Ekehammer (1980). 
The factor technological progress reflects a cultural change in political attitudes. A few decades ago, a similar factor might have been a near opposite of general conservatism, which is defined as tendency to oppose change in institutions and methods. This factor reflects a concern with the negative consequences of technological (e.g. nuclear power plants) and social change (e.g. pornography) which is nowadays found throughout the political spectrum. Factor four, taxation, summarizes the recent debate about the means to achieve important and broadly shared societal goals (reunification of Germany, environmental protection). Due to our focus on political issues related to the ministries of the Federal Government, items referring to religious issues are only marginally represented in our item pool and thus have no chance to emerge as a separate factor.

Besides this rotated factor structure, we considered the relation between unrotated factors and personality. The first unrotated factor is easily identified as a broad factor of general conservatism. However, there is no evidence that any remaining unrotated factor is more clearly related to the five personality dimensions than the rotated factors as has been suggested by Eysenck (1954) and Eysenck and Wilson (1978).

The most striking result of our study is the high negative correlation of openness to experience with general conservatism. This correlation is not a trivial result of item content. Only two of the items of the NEO-FFI are loosely related to political attitudes (one refers to religious authorities, the other to the presentation of controversial issues in schools). Wilson (1973) characterizes conservatism as a broad personality dimension, which he describes as a general dislike of uncertainty. Conservative respondents are described as people that seek familiarity, simplicity, and safety. Openness to experience, on the other hand "assesses the proactive seeking and appreciation of experience for its own sake [and] toleration for and exploration of the unfamiliar" (Costa \& McCrae, 1985, p. 2). The negative relationship between these two concepts that can be expected from these descriptions has been found in our data. Wilson's description of conservatism points to an explanation of conservatism in terms of Zuckerman's (1979) concept of sensation seeking. This explanation would postulate similar processes underlying both individual differences in openness to experience and general conservatism, which is best operationalized by the first unrotated principal component.

The view that tolerance for the unfamiliar and dislike of uncertainty is a common feature of conservatism and openness is also in line with our results for the rotated subfactors conservatism, social welfare, and taxation for environmental protection and the development of East Europe, but seems at odds with the lack of a positive correlation of openness with the factor technological progress. However, affirmation of technological progress may not only be based on the acceptance of the risks and social changes that may accompany the introduction of new technologies, but may reflect faith in the authorities' guarantees of safety and capabilities to control and handle new developments.

The remaining dimensions of the five-factor model are plausibly linked to political attitudes, although the relationships do not always confirm our predictions. Contrary to our expectations, neuroticism tends to show a weak negative correlation with conservatism and is negatively related to technological progress. It seems reasonable to assume that individual differences in anxiety link neuroticism to this factor on which items have high loadings that favor potentially dangerous technologies and social changes that may be harmful to certain groups within our society. Also unexpectedly, extraversion shows a positive correlation with general conservatism, which is significant for the first unrotated factor. The negative correlation with taxation gives rise to the speculation that the correlation of extraversion with conservatism depends on the contents of the conservatism measure. In our study no items were included that referred directly to general morality, sexual freedom, or religiosity. The correlation of extraversion with conservatism may, however, be influenced by the degree to which conservatism implies a restriction of personal freedom, as does an increase in taxation.

The correlations for agreeableness show a pattern that can be regarded as a simple projection of interpersonal behavior onto the domain of political attitudes. High scorers on agreeableness are less conservative (indicate, e.g. less ethnocentrism or punitiveness), favor social welfare, are against potentially harmful technologies or social changes, and affirm an increase in taxation for legitimate goals. Contrary to our expectations, conscientiousness shows a different pattern of correlations, which implies that the correlations of agreeableness and conscientiousness with political attitudes 
are not caused by a common underlying dimension (psychoticism). Conscientiousness correlates positively with conservatism. Although these correlations are weak when we control for demographic variables, this correlation fits with 'law and order' stereotype. Conscientiousness is not correlated with any of the other attitude factors.

No clearly interpretable curvilinear relations between attitude dimensions and the five-factor model were found. Only the correlation between extremity on the rotated conservatism dimension and conscientiousness is significant, when we control for demographic and personality variables. This weak and unexpected correlation warrants no interpretation.

As expected, we found a substantial correlation between age and conservatism. However, our data do not suggest an explanation of this effect, which is still substantial, even when we control for personality characteristics. The expected lower conservatism scores among females were not found in our data, but sex is significantly related to technological progress. This result may be attributed to a greater familiarity of males with technology, which might be a result of the socialization process. Note, that sex is not related to the factor social welfare and support of women's equality, indicating that women's equality and the affirmation of measures to achieve this goal (like child care centers, preschools) is equally supported by men and women.

To conclude, our study has demonstrated meaningful links between the five-factor model of personality and political attitudes. The inclusion of the five-factor model into studies of attitudes seems promising. It provides a frame of reference for the integration of research findings.

\section{REFERENCES}

Allport, G. W. (1937). Personality: A psychological interpretation. New York: Holt.

Avery, P. G. (1988). Political tolerance among adolescents. Social Behavior, 16, 183-201.

Borkenau, P. \& Ostendorf, F. (1991). Ein Fragebogen zur Erfassung fünf robuster Persönlichkeitsfaktoren [A questionnaire to measure five robust personality factors]. Diagnostica, 37, 29-41.

Cattell, R. B. (1950). Personality: A systematic theoretical and factual study. New York: McGraw-Hill.

Costa, P. T. \& McCrae, R. R. (1977). Age differences in personality structure revisited: Studies in validity, stability, and change. Age and Human Detelopment, 8, 261-275.

Costa, P. T. \& McCrae, R. R. (1978). Objective personality assessment. In Storandt, M., Siegler, I. C. \& Elias, M. F. (Eds), The clinical psychology of aging (pp. 119-143). New York: Plenum Press.

Costa, P. T. \& McCrae, R. R. (1985). The NEO Personality Inventory manual. Odessa, FL: Psychological Assessment Resources.

Costa, P. T. \& McCrae, R. R. (1989). The NEO PI/FFI manual supplement. Odessa, FL: Psychological Assessment Resources.

Costa, P. T. \& McCrae, R. R. (1992). Four ways five factors are basic. Personality and Individual Differences, 13, 653-665.

Ekehammar, B. (1985). Sex differences in sociopolitical attitudes revisited. Educational Studies, 11, 3-9.

Ekehammar, B. \& Sidanius, J. (1982). Sex differences in socio political attitudes: A replication and extension. British Journal of Social Psychology, 21, 249-257.

Eysenck, H. J. (1954). The psychology of politics. New York: Praeger.

Eysenck, H. J. (1971). Social attitudes and social class. British Journal of Social and Clinical Psychology, 10, $201-212$.

Eysenck, H. J. (1992). Four ways five factors are not basic. Personality and Individual Differences, 13, 667-673.

Eysenck, H. J. \& Coulter, T. T. (1972). The personality and attitudes of working class British communists and fascists. The Journal of Social Psychology, 87, 59-73.

Eysenck, H. J. \& Eysenck, M. (1985). Personality and individual differences; A natural science approach. New York: Plenum.

Eysenck, H. J. \& Eysenck, S. B. G. (1976). Psychoticism as a dimension of personality. London: Routledge \& Kegan.

Eysenck, H. J. \& Wilson, G. D. (Eds) (1978). The psychology of ideology. Baltimore, MD: University Park Press.

Feather. N. T. (1977). Value importance, conservatism and age. European Journal of Social Psychology, 2, $241-245$.

Fiske, D. W. (1949). Consistency of the factorial structures of personality ratings from different sources. Journal of Abnormal and Social Psychology, 44, 329-344.

Furnham, A. (1985). Adolescents' sociopolitical attitudes: A study of sex and national differences. Political Psychology, 6, 621-636.

Glamser, F. D. (1974). The importance of age to conservative opinions: A multivariate analysis. Journal of Gerontology, $29,549-554$.

Glasgow, N. R., Cartier, A. N. \& Wilson, G. D. (1985). Conservatism, sensation-seeking and music preferences. Personality and Individual Differences, 6, 395-396.

Guilford, J. P. (1964). Personality. New York: McGraw-Hill.

Heaven, P. C. L. \& Connors, J. (1988). Politics and tough mindedness. The Journal of Social Psychology, 128, $217-222$.

Kerlinger, F., Middendorp, C. P. \& Amon, J. (1976). The structure of social attitudes in three countries: Test of a critical referent theory. International Journal of Psychology, 11, 265-279.

Kish, G. B., Netterberg, E. E. \& Leahy, L. (1973). Stimulus-seeking and conservatisin. Journal of Clinical Psychology, 29, $17-20$.

Kline, P. \& Lapham, S. L. (1991). The validity of the PPQ: A study of its factor structure and its relationship to the EPQ. Personality and Individual Differences, 12,63I-635.

Kopinak, K. (1987). Gender differences in political ideology in Canada. Canadian Review of Sociology and Anthropology, $24,23-38$ 
Looft, W. R. (1971). Conservatives, liberals, radicals and sensation-seekers. Perceptual and Motor Skills, $23,98$.

Lupfer, M. B. \& Rosenberg, J. P. (1983). Differences in adults' political orientations as a function of age. Journal of Social Psychology, 119, 125-133.

McCrae, R. R. (1987). Creativity, divergent thinking, and openness to experience. Journal of Personality and Social Psychology, 52, 1258-1265.

McCrae, R. R. \& Costa, P. T. (1985a). Comparison of EPI and psychoticism scales with measures of the five-factor model of personality. Personality and Individual Differences, 6, 587-597.

McCrae, R. R. \& Costa, P. T. (1985b). Openness to experience. In Hogan, R. \& Jones, W. H. (Eds), Perspectives in personality: A research annual (Vol. 1, pp. 145-172). Greenwich, CT: JAI Press.

Murray, H. A. (1938). Explorations in personality. New York: Oxford University Press.

Norman, W. T. (1963). Toward an adequate taxonomy of personality attributes. Replicated factor structure in peer nomination personality ratings. Journal of Abnormal and Social Psychology, 66, 574-583.

Ojha, H. \& Sah, B. (1990). Personality and socio-familial correlates of conservatism in Indian youth. International Journal of Psychology, 25, 295-304.

Pearson, P. R. \& Greatorex, B. J. (1981). Do tough-minded people hold tough-minded attitudes? Current Psychological Research, 1, 45-48.

Pearson, P. R. \& Sheffield, B. F. (1975). Social attitude correlates of sensation-seeking in psychiatric patients. Perceptual and Motor Skills, 40, 482.

Powell, G. E. \& Stewart, R. A. (1978). The relationship of age, scx and personality to social attitudes in children aged 8-15 years. British Journal of Social and Clinical Psychology, 17, 307-317.

Ray, J. J. (1979). Does authoritarianism of personality go with conservatism? Australian Journal of Psychology, 31, 9-14.

Ray, J. J. (1985). Authoritarianism of the left revisited. Personality and Individual Differences, 6, 271-272.

Rokeach, M. (1960). The open and closed mind. New York: Basic Books.

Schiebel, B. Riemann, R. \& Mummendey, H. D. (1984). Eine aktualisierte deutschsprachige Form der Konservatismusskala von Wilson \& Patterson [An actualized German version of Wilson and Patterson's conservatism scale]. Zeitschrift für Differentielle und Diagnostische Psychologie, 5, 311-321.

Sidanius, J. \& Ekehammer, B. (1980). Sex-related differences in socio-political ideology. Scandinavian Journal of Psychology, $21,17-26$

Smithers, A. G. \& Lobley, D. M. (1978). Dogmatism, social attitudes and personality. British Journal of Social and Clinical Psychology, 17, 135-142.

Tupes, E. C. \& Christal, R. E. (1961). Recurrent personality factors based on trait ratings. USAF Technical Report ASD-IR-61-97.

Vleeming, R. G. (1985). Factors affecting attitudes toward nuclear power in the Netherlands. Journal of Social Psychology, $125,119-125$.

Wilson, G. D. (1973). The psychology of conservatism. London: Academic Press.

Wilson, G. D. (1975). Manual for the Wilson Patterson Attitude Inventory. Winsor: NFER.

Wilson, G. D. (1985). The 'catchphrase' approach to attitude measurement. Personality and Individual Differences, 6, 31-37.

Wilson, G. D. \& Brazendale, A. H. (1973). Social attitude correlates of Eysenck's personality dimensions. Social Behavior and Personality, $1,115-118$.

Wilson, G. D. \& Patterson, J. R. (1968). A new measure of conservatism. British Journal of Social and Clinical Psychology, 7, 264-269.

Zuckerman, M. (1979). Sensation Seeking: Beyond the optimal level of arousal. New York: Erlbaum.

Zuckerman, M. (1992). What is a basic factor and which factors are basic? Turtles all the way down. Personality and Individual Differences, 13, 675-681.

Zweigenhaft, R. L. (1985). Race, sex, and nuclear war. Genetic, Social, and General Psychology Monographs, 111, $283-301$. 